\title{
An overview: biomolecules from microalgae for animal feed and aquaculture
}

\author{
Zahira Yaakob ${ }^{1}$, Ehsan Ali ${ }^{*}$, Afifi Zainal ${ }^{1}$, Masita Mohamad ${ }^{1}$ and Mohd Sobri Takriff ${ }^{1}$
}

\begin{abstract}
Despite being more popular for biofuel, microalgae have gained a lot of attention as a source of biomolecules and biomass for feed purposes. Algae farming can be established using land as well as sea and strategies can be designed in order to gain the products of specific interest in the optimal way. A general overview of the contributions of Algae to meet the requirements of nutrients in animal/aquaculture feed is presented in this study. In addition to its applications in animal/aquaculture feed, algae can produce a number of biomolecules including astaxanthin, lutein, beta-carotene, chlorophyll, phycobiliprotein, Polyunsaturated Fatty Acids (PUFAs), beta-1,3-glucan, and pharmaceutical and nutraceutical compounds which have been reviewed with respect to their commercial importance and current status. The review is further extended to highlight the adequate utilization of value added products in the feeds for livestock, poultry and aquaculture (with emphasis in shrimp farming).
\end{abstract}

Keywords: Microalgae, Carotenoid, Biomolecules, Nutraceutical, Aquaculture, Animal feed

\section{Introduction}

Nutritional composition of algae is well documented and it mainly contains proteins, carbohydrates, lipids and trace nutrients, including vitamins, antioxidants, and trace elements. These all algal components have the characteristics to be a natural supplement in human and animal feed to replace synthetic components or meet the increasing demands of such ingredients. Increased consumption of animal proteins is creating a towering demand of high quality fish and animal feed to generate healthy proteins for humans. Fish meal is the protein source traditionally used in aquaculture diets but it is considered as limited and expensive. The nutritional contents of algae are rapidly gaining importance as a renewable source to substitute the conventional ingredients in the aquaculture/animal feed. Algae is defined as heterogeneous assemblage of organisms that range in size from tiny cells to giant seaweeds, thus algae mostly are photosynthetic species which includes eukaryotes and prokaryotic Cyanobacteria (blue-green algae) and live in aquatic habitats. Algae can be differentiated (by the body size and structure) either to microalgae (with algal bodies that need microscope to be observed)

\footnotetext{
* Correspondence: insnalidr@gmail.com

${ }^{2}$ Centre for Energy Systems, National University of Sciences and Technology, Sector H-12, Islamabad, Pakistan

Full list of author information is available at the end of the article
}

or to macroalgae (large enough to be seen with unaided eye) [1]. Algae culturing has been adopted since the late of 1800s and early 1900s, while microalgae mass culturing begin to develop since the achievement of Allen and Nelson in 1910 by cultivating Chlorella sp. for aquaculture purposes in Berlin, Germany [2]. To date, it seems that microalgae have the potential to play pivotal roles in order to remedy the energy, environment and food crisis prevailing in the world. This review encompasses the roles of algae in biomolecules production including astaxanthin, lutein, beta carotene, chlorophyll, phycobiliprotein, Polyunsaturated Fatty Acids (PUFAs), beta-1,3glucan, and pharmaceutical and nutraceutical compounds. This review also emphasizes on the utilization of these biomolecules in livestock, poultry and aquaculture (and especially shrimp farming) feed.

\section{Review}

Production of value added products from algae

The global carotenoids market is projected to reach US $\$ 1.2$ billion by the year 2015, because of the rising consumer awareness about health benefits offered by various carotenoids, and the shift towards healthy and natural food products (Global Industry Analysts, Inc http://www. strategyr.com/Carotenoids_Market_Report.asp/). According to a recently published report, global carotenoids 
market tends to reach US\$1.3 billion by 2017 (http:// www.prweb.com/pdfdownload/8849957.pdf). The nutraceuticals boom has also integrated carotenoid mainly on the claim of their proven antioxidant properties; carotenoids are usually considered important for industrial use in food products, cosmetics as vitamin supplements, health food products, and as feed additives for poultry, livestock, fish, and crustaceans [3]. In contrast, carotenoid in fish oil comes from microalgae, therefore it is logical to cultivate microalgae for carotenoids production [4]. Del Campo et al. [3] have reported that structure of more than 600 different carotenoids have been derived from a 40-carbon polyene chain. This paper will focus on carotenoids such as astaxanthin, lutein, beta-carotene and other highvalued molecules which are produced by microalgae (or in some case by macro algae) and Cyanobacteria and can be industrialized. Moreover, microalgae play a key role in high grade animal nutrition food from aquaculture to farm animals. Comprehensive nutritional and toxicological evaluations have demonstrated suitability of algal biomass as a valuable feed supplement or substitute for conventional animal feed sources [5]. Therefore, the usage of microalgae biomass for feed productions will be discussed in this review which might be helpful to encourage the trends of mass cultivation of microalgae for commercial and beneficial purposes.

\section{Astaxanthin}

Astaxanthin, a carotenoid equipped with two asymmetric carbon located at the 3 and $3^{\prime}$ position of the benzenoid rings on either end of the molecule, has been proposed as super vitamin E due to its natural antioxidant activities [6-8]. As a natural pigment, the major market for astaxanthin is as pigmentation source in aquaculture [9]. Natural astaxanthin can be produced by Haematococcus microalgae, Chlorella zofingiensis, Chlorococcum sp. and the yeast Xanthophyllomyces dendrorhous [10-13]. Studies regarding effects on lipid metabolism and antioxidant defense mechanisms revealed that astaxanthin is responsible for lowering the plasma lipid concentrations and enhancing antioxidant defense in apolipoprotein E knockout mice [14]. The increasing growth of salmonid farming has created an enormous demand for natural astaxanthin as pigment. Out of total carotenoid (astaxanthin, cantaxanthin), the astaxanthin was determined as the most important carotenoid in salmons and rainbow trouts [15]. Salmonid are unable to synthesize astaxanthin de novo, therefore carotenoid pigments must be supplied in their artificial aquaculture diet [16]. The carotenoid pigment astaxanthin has important applications and is routinely being used in the nutraceutical, cosmetics, food and feed industries [17]. In aquaculture feed, it has been used to culture salmon, shrimp, ornamental fish and sea bream. A recent report showed that Haematococcus pluvialis especially in dose of $3 \mathrm{~g} \mathrm{~kg}^{-1}$ feed administration may effectively enhance the antioxidant system and some biochemical parameters in rainbow trout [18]. Astaxanthin is not responsible only to provide pigmentation but also has been attributed with extraordinary potential for protecting the organism against a wide range of diseases, and has considerable potential and promising applications in human health [13]. Natural astaxanthin was also found effective to treat the patients with functional dyspepsia, caused by Helicobacter pylori [7]. UV radiation from sunlight is known as the most potent environmental risk factor in skin cancer pathogenesis, astaxanthin has been demonstrated as a protective tool against UVA-induced DNA alterations in human skin fibroblasts (1BR-3) [19].

Epidemiological studies have demonstrated a correlation between increased carotenoid intake and reduced incidence of coronary heart disease, certain cancer types, macular degeneration, and increased resistance to viral, bacterial, fungal and parasitic infection [20]. The price for astaxanthin varies in the market and depends on the percentage contents in algal source; however the overall maintained price of $5 \%$ astaxanthin is about US $\$ 1900 \mathrm{~kg}^{-1}$ (http://www.herbridge.com/bencandy.php? fid-55-id-23446-page-1.htm).

\section{Lutein}

Lutein is another important carotenoid which can be found naturally in algae. It is prominent in human serum and foods [21]. Lutein has been used for the pigmentation of animal tissues and products, and it is considered important for the natural coloration of foods, drugs and cosmetics. It has been documented that it plays an active role in delaying chronic diseases, stimulating the immune response, hampering the development of cataracts and the progression of early atherosclerosis, and preventing blindness or decrease in vision caused by age-related macular degeneration [22-24]. Global lutein market in 2004 accounted for US\$139 million and was considered as the fastest projected growth in individual carotenoids sales [3]. The recent market value of lutein is US\$233 million (2010), and is expected to reach US $\$ 309$ million by 2018 with a compound annual growth rate of $3.6 \%$ (http://www.companiesandmarkets.com/ Market/Food-and-Drink/Market-Research/The-GlobalMarket-for-Carotenoids/RPT988273). French marigold (Tagetes patula) is currently the most widely applied source for lutein production in the world. In the USA, two lutein containing products, Aztec Marigold and Tagetes have been commercialized. Lutein is usually produced from three different marigold flowers (Tagetes patula L.) (marigold orange, marigold yellow, and marigold red) but the marigold orange (MGO) variety 
contains the maximum amount of lutein [25]. However, mass plantation of marigold occupies a large land area and it is easily influenced by seasonal and climatic change [24]. Although an established commercial system for the production of lutein from microalgae does not exist yet, the basis for outdoor production of lutein-rich cells of strains of Muriellopsis sp. and Scenedesmus sp. at a pilot scale have already been set up [3]. Recently, there has been remarkable interest in dietary carotenoids with respect to their antioxidant properties and their ability to reduce the chances of some chronic diseases which occurred because of the free radicals. Possibly, carotenoids protect cells from oxidative stress by quenching singlet oxygen damage with a variety of mechanisms. Therefore, algae derived carotenoids could be a leading natural resource in the search of potential functional ingredients [26]. The microalgae biomass from chlorophycean is also considered as the major source of lutein, especially Chlorella sp., Scenedesmus sp. and Muriellopsis sp. [3,24]. Laboratory studies showed that heterotrophically cultivated Chlorella sp. produce considerable amount of lutein [27]. The ability of heterotrophic growth in fermenters makes Chlorella sp. a potential alternative resource for commercial production of lutein [24]. Studies showed that more lutein will be produced by Chlorella sp. using Basal Medium compared to Kuhl Medium because of the high concentration of EDTA and minerals $\left(500 \mathrm{mg} \mathrm{l}^{-1}\right.$ : $9.3 \mathrm{mg} \mathrm{l}^{-1}$ ) [22]. On the other hand, Wu et al. [24] have modeled lutein production by heterotrophic Chlorella sp. in batch and fed-batch cultures as a potential alternative source for commercial production.

\section{Beta-carotene}

Beta-carotene is a pigment of increasing demand and a wide variety of market applications: as food coloring agent, pro-vitamin A (retinol) in food and animal feed, additive to cosmetics and multivitamin preparations, and as a health food product under the antioxidant category. The market value of beta-carotene was estimated about US\$253 million in 2009 [3]. According to a report on the global market for carotenoids (September 2001), the market value of beta-carotene was estimated at around US $\$ 261$ million in 2010 and this market is expected to grow to US\$334 million by 2018 at a compound annual growth rate of $3 \%$ (http://www.companiesandmarkets. $\mathrm{com} / \mathrm{News} /$ Chemicals/Beta-carotene-the-Largest-Carotenoid-Sector-is-Forecast-to-be-Worth-US-334-Mn-by-2018/ NI2439).

Because of limited supply from natural sources, a number of companies have introduced synthetically produced carotenoids to meet the high demands in the global market. Beta-carotene, a provitamin A is the only carotenoid which has the potential to form two molecules of vitamin
A (retinol) [28]. Natural production of beta-carotene can be produced by the microalgae genus Dunaliella, strains that have shown to change their color from green to orange may produce and accumulate large amount of cellular beta-carotene [29]. Dunaliella sp. occurs in oceans, brine lakes, salt marshes, salt lagoon and salt water ditches near sea, predominantly in water bodies containing more than $2 \mathrm{M}$ salt and high level of magnesium. Dunaliella sp. is recognized as being the most halotolerant eukaryotic photosynthetic organism, showing a remarkable degree of adaptation to variety of salt concentrations from as low as $0.1 \mathrm{M}$ to salt saturation about $4 \mathrm{M}$ [30]. The unicellular halotolerant alga Dunaliella bardawil was shown to contain high concentration of beta-carotene, composed of the all-trans and the 9-cis isomers [28]. Beta-carotene is a structural analogue of vitamin A and its topical application can effectively be used to treat skin melasma [31]. It has been reported that a daily dose of Dunaliella sp. beta-carotene exerts a protective effect against exercise induced asthma probably through in vivo antioxidative effect [32]. Age-related macular degeneration is one of the most common eye diseases causing severe or permanent loss of vision, an antioxidant therapy using combinations of high dosage antioxidant vitamins $\mathrm{C}, \mathrm{E}$, beta-carotene, and zinc are employed $[33,34]$.

The price for natural beta-carotene depends on demand varying from US $\$ 300$ to US $\$ 3000 \mathrm{~kg}^{-1}$. Purified beta-carotene is sold in vegetable oil form ranging from $1 \%$ to $20 \%$ of concentration depending on type of food products. Naturally produced purified beta-carotene is usually accompanied with other Dunaliella sp. carotenoid (carotenoid mix) which includes lutein, neoxanthin, zeaxanthin, violaxanthin, cryptoxanthin, and $\alpha$-carotene. Variety of natural beta-carotene can be found for sale as health food and supplement under vitamin section. In powder form, natural beta-carotene is used for colorization and pro-vitamin A for animal (cattle and poultry) and aquaculture (shrimp and fish) feed [30].

\section{Chlorophyll}

Chlorophyll is a green pigment and is an extremely important biomolecule, critical in photosynthesis, which allows plants to absorb energy from light for carbon dioxide fixation. The most green leaf material contains about $0.3 \%$ chlorophyll and on extraction using conventional methods yields about only $5 \%$. Cheap sources, like grass and lucerne (alfalfa), are usually selected as chlorophyll source [35]. In more esoteric extractions, leaves of nettles and elder are preferred, whilst algae and silk worm droppings have also been used commercially [36].

Structurally, chlorophyll is essentially two parts: a substituted porphyrin ring known as an excellent chelating ligand and a long carbon chain phytol [37]. Dietary 
chlorophyll is predominantly composed of lipophilic derivatives including chlorophyll $\mathrm{a}$ and $\mathrm{b}$. The structural modifications of the chlorophyll pigments mainly the de-esterification of phytol ring may significantly increase (65-fold) its transfer from the food matrix to the intestinal epithelial cells during digestion [38]. Sodium/ copper derivatives of chlorophyll are frequently used as food additives or in beverages [39]. Sodium copper chlorophyllin is an approved food color in the USA (http://www. accessdata.fda.gov/scripts/cdrh/cfdocs/cfCFR/CFRSearch. $\mathrm{cfm}$ ? $\mathrm{fr}=73.125)$. Besides that, it repairs cells, increases hemoglobin in blood and promotes the cell growth [5]. Regarding the cytotoxity of chlorophyll derivatives, the application of pheophorbide and pheophytin against tumor cell revealed that the cellular uptake and inhibition of myeloma cell multiplicity was greater for pheophorbide than pheophytin, hence it indicates that chlorophyll derivates may play a role in cancer prevention [28]. Patients with chronic relapsing pancreatitis can be treated with chlorophyll- $\alpha$ without any unfavorable side-effects, such as of allergic, or photosensitive, or hepatotoxic nature [40].

Chlorophyll has also been investigated as potential source of pigments in cosmetics; the brown and red algae are mostly used in the cosmetic industries [5]. Furthermore, in food industry, chlorophyll is used as natural pigment ingredient in processed foods. Because of its strong green pigment and consumer demand for natural foods, chlorophyll is gaining importance as food additive. This in turn is encouraging food processors to switch from artificial pigments to chlorophyll-based natural coloring. However, a downstream process needs to be developed to purify chlorophyll a and b from algae [5].

\section{Phycobiliproteins}

Phycobiliprotein, a high-potential molecule, has been utilized commercially as natural dyes and has a variety of applications in pharmaceutical industry. It is classified according to UV-visible absorption maxima as phycocyanin (blue pigment), phycoerythrins (red pigment), and allophycocyanin (pale-blue pigment). The annual market of phycocyanin was around US\$5-10 million [41]. The Cyanobacterium Spirulina sp. is a source of c-phycocyanins and allophycocyanins and contains relatively low nucleic acid content; is composed of $55 \%-70 \%$ protein, $6 \%-9 \%$ fat, and $15 \%-20 \%$ carbohydrate, and is rich in minerals, vitamins, fibres, and pigments [42]. Another type of algae that can be a source for phycobiliprotein is Aphanizomenon flos-aquae [28,43]. Arthrospira sp. is a group of Cyanobacteria characterized by loosely spiral shaped trichomes arranged in an open helix enclosed in a thin mucilaginous sheath, usually found in alkaline, brackish and saline waters. They usually become predominant species and form massive blooms [44]. The phycobiliprotein may be utilized for labeling antibodies in clinical tests (such as immunofluoresscence or flow cytometry) by binding to biologically active molecules such as immunoglobulin, biotin or protein $[28,45]$. Scientific studies have shown that the synergistic action of a wide spectrum of antioxidants is better than the activity of a single antioxidant, and that antioxidants from natural sources (primarily foods) have a higher bioavailability and therefore higher protective efficacy than synthetic antioxidants [43]. It is reported that phycocyanin acts as antioxidant against free radicals and selenium and phycocyanin have been reported to show potent cancer chemopreventive activities [46,47]. It is proven that phycocyanin is 20 times more efficient than ascorbic acid against hemolysis induced by peroxyl radicals in human erythrocytes [28].

\section{Polyunsaturated fatty acids (PUFAs)}

Polyunsaturated Fatty Acids (PUFAs) include docosahexaenoic acid (DHA), eicosapentaenoic acid (EPA), arachidonic acid (AA), $\gamma$-linolenic acid (GLA) and have been widely recognized as beneficial towards human health [48]. According to a new technical market research report "Global Market for Oleochemical Fatty Acids" (CHM062A) from BCC Research (www.bccresearch. com), the naturally produced fatty acid market was valued at US\$7.2 billion in 2011 and should reach US\$6.9 billion in 2012. The total market value of fatty acids expected to reach US\$13 billion in 2017 (http://www. slideshare.net/bccresearch).

Natural PUFAs can be obtained from fish or extracted from fish oil. However, there is report on the possibility of accumulated toxin in the PUFAs derived from fish sources, furthermore the unpleasant smell, taste and poor oxidative stability has limits the application of fish oil as food additive [4]. Fish oil derived PUFAs have low oxidative stability and the oxidative stability of DHA containing algae oils varies widely depending on some physical parameters. However, EDTA can be used to inhibit oxidation of foods containing long-chain PUFA from either fish or algae and fortified with iron [49]. Moreover, a recent study has shown that PUFAs $\left(450 \mathrm{mg} \mathrm{day}^{-1}\right.$ ) are not being met by the diet in the majority of the population; the current mean intake of PUFAs by adults is estimated to be about $282 \mathrm{mg}^{-1 a y}{ }^{-1}$ (EPA and DHA contributing about $244 \mathrm{mg} \mathrm{day}^{-1}$ ) [48]. It is undeniable that microalgae can be the alternative natural source for PUFAs; PUFAs found in fish are actually originated from microalgae. However, DHA is the only algal PUFA commercially available as an omega- 3 fatty acid and has been documented as a major structural fatty acid in the grey matter of the brain [50]. DHA is important for correct brain and eye development in infants and has been shown to support cardiovascular health in adults $[4,51]$. DHA helps body to fight against diseases and recent studies explore the significant role of PUFAs in the immune system 
through peroxisome proliferator-activated receptors (PPAR- $\alpha$ and PPAR- $\gamma$ ), and favorable effects of $n-3$ PUFA supplementation on allergic diseases and novel therapeutic strategies to treat eosinophilic disorders have also been reported [52].

Marine microalgae have significantly higher DHA contents compared to fresh water microalgae [5]. DHA is found in a limited selection of foods such as fatty fish and organic meat; it also occurs naturally in breast milk and its concentration in breast milk might be influenced by environmental factors, however it is not available in cow's milk [53]. Since 1990, a number of health and nutrition organizations have specifically recommended the inclusion of DHA in infant formula for preterm and full term infants. DHA is the characteristic PUFA of the marine dinoflagellates. Crypthecodinium cohnii is a non-photosynthetic, marine dinoflagellate producing DHA predominantly [54]. Nearly $30-50 \%$ of its constituent fatty acids are C22:6 (n-3) fatty acid and no other PUFAs are present in excess of $1 \%$. It is, thus easy to separate DHA from the fatty acid mixtures. For this reason, Crypthecodinium cohnii represents a promising source for the commercial production of DHA [55]. The world wholesale market for infant formula was estimated to be about US\$10 billion per year [56]. A number of food items containing PUFAs (including DHA) are being sold in market [4]. Some algae-related heterotroph strains that have high DHA such as Schizochytrium mangrove, reported to have main component of DHA in a range of $33-39 \%$ of total fatty acid while Amphidium caryerea and Thrautocytrium aureum contain $17 \%$ and $16.1 \%$, respectively [5].

Nannochloropsis $s p$. has been proposed as a source of PUFAs due to its high contents of EPA [57]. Thus, Nannochloropsis $s p$. production has been used to address the rotifer requirements of 8 million gilt-head sea bream fingerlings production annually [58]. Being suitable for aquaculture industry, EPA too has been used as nutritional supplement. The diatoms Phaeodactylum tricornutum and Nitzschia laevis are algae strains to be utilized as sources of EPA $[4,59]$. Chaetoceros muelleri var. subsalsum and Isochrysis galbana have record percentage of DHA and EPA; they present the highest output of EPA ( $3.5 \%$ and $4.8 \%$ on dry basis, respectively) using vertical plate glass reactor $[58,60]$. EPA is an $n-3$ PUFA that plays an important role in the regulation of biological functions and prevention and treatment of a number of human diseases such as heart and inflammatory diseases [61]. The eicosanoids are hormonelike substances including prostaglandins (PG), thromboxanes (TX) and leukotrienes (LT). AA and EPA are precursors of eicosanoid compounds. However, the eicosanoids from these two fatty acids are different structurally and functionally, and are sometimes even antagonistic in their effects. A balanced uptake of EPA/AA can prevent eicosanoid dysfunctions and may be effective in treating a number of illnesses and metabolic disorder [59]. Porphyridium cruentum, a red alga, has been used for massive cultures due to its relatively high AA and EPA concentration. Nevertheless, Porphyridium cruentum biomass is high in protein (34.1\%), carbohydrates (32.1\%) and essential minerals [62]. AA is potentially used for infant formulas (either for full-term or preterm infants) and as nutritional supplement [4].

Aside from phycobiliprotein, Arthrospira sp. is known to be the richest algal source of GLA. GLA is important to the infant formulas for full-term infant and has the potential to lower low-density lipoproteins in hypercholesterolemic patients, alleviate the premenstrual syndrome and treat atopical eczema $[4,44]$. GLA may attenuate the signs and symptoms of inflammatory diseases such as rheumatoid arthritis and atopic dermatitis [63,64]. From both animal and human trials, it has been revealed that dietary supplementation with GLA can modulate inflammation [63].

\section{Beta-1,3-glucan}

Beta-1,3-glucanis considered responsible to initiate host defense reactions in response to pathogen surface molecules. The most important substance other than oil in Chlorella sp. is beta-1,3-glucan. The world annual sales of Chlorella sp. are in excess of US\$ 38 billion [65]. Initially, beta-1,3-glucan was named as Zymosan in the 1940s in Norway. It was found in the cell wall of baker's yeast. Further studies have been conducted by Riggi \& Di Luuzio in 1961 [66] in Italy, and since then the bioactive compound was renamed as beta-1,3-glucan. Further studies on beta-1,3-glucan has been done in Japan around 1970s. Beta-1,3-glucan is important to human health. Feeding of immunostimulant beta-1,3-glucan to healthy fish may raise the non-specific and specific immunity level and the protection against bacterial infection compared with the control [67]. Chlorella sp. is a major source of beta-1,3-glucan [68]. Beta-1,3-glucan had significant effect as a prophylactic treatment to reduce the anthrax infection in mice and the same type of treatment can also inhibit the growth of cancer cells in vivo by involving stimulation of three important cytokines $[69,70]$. Positive effects were also found in patients after cardiopulmonary bypass, and inhibition of antiviral activity has been found in HIV-infected patients, moreover beta-1,3-glucans are routinely used in patients for tumor immunotherapy [71]. The use of beta-1,3-glucan is of special interest in the cancer patient undergoing chemotherapy and/or radiation treatment, since betaglucans have shown a remarkable ability to accelerate hematopoetic recovery in both sublethally and lethally irradiated mice. It can also stimulate recovery of the bone marrow following chemotherapy, which is vital to 
restricting tumor growth and preventing infectious complications during treatment. Amparyup et al. [72] showed that pattern recognition proteins [including lipopolysaccharide and beta-1,3-glucan binding protein (LGBP)] could enhance the phenoloxidase activity in shrimp.

\section{Pharmaceutical and nutraceutical compounds}

Algae have the potential to be a source of compounds having antibiotic and anticancer activity. A wide variety of Cyanobacteria produce compounds including sulfolipids that were active against herpes virus, pneumonia virus and HIV [73,74]. Cyanobacteria can produce tolytoxin (6-hydroxy-7-O-methylscytophycin B), an antifungal antibiotic and highly toxic to mice $[75,76]$. The marine cyanobacterium Lyngbya majuscula produces aurilides $\mathrm{B}$ and $\mathrm{C}$ having cytotoxicity against human lung tumor and mouse neuroblastoma cell line [77]. Moreover the macroalgae Laphocladia sp. is capable of producing lophocladine alkaloids that exhibit cytotoxicity to NCI-H460 human lung tumor and MDA-MB435 breast cancer cell lines [78]. Therefore, once the algal sources of useful medicinal compound are identified, the algae can be cultivated in mass scale and the material can be extracted, purified, and marketed [1]. Some microalgae species are established in the skin care market, the main ones being Arthrospira sp. and Chlorella sp. A number of cosmeticians have even invested in their own microalgae production (http://www.fao.org/docrep/ 012/i1704e/i1704e01.pdf). Two examples of commercially available products and their properties claimed by their companies are a) a protein-rich extract from Arthrospira sp. that repairs the signs of early skin aging, exerts a tightening effect and prevents stria formation [4] (Protulines, Exsymol S.A.M., Monaco) and b) an extract from Chlorella vulgaris that stimulates collagen synthesis in skin, thereby supporting tissue regeneration and wrinkle reduction (Dermochlorella, Codif, St. Malo, France http:// www.coptis.com/site/desc.php?RefFab=1CDF). Recently, two new products have been launched by Pentapharm (Basel, Switzerland): a compound from Nannochloropsis oculata is used for excellent skin-tightening properties (short and long-term effects) (Pepha-Tight) and an ingredient from $D$. salina is known to have the ability to markedly stimulate cell proliferation and turnover to positively influence the energy metabolism of skin (Pepha-Ctive) [4].

\section{Livestock feed}

Spirulina has been frequently used in feed supplements due to its excellent nutrient compounds and digestibility because it has small amount of carbohydrates. The livestock feed is another useful product which may be obtained from the algae, since many of algae species have been examined for their biochemical compositions to evaluate their suitability as a substitute or primary livestock feed [79].
Spirulina has a unique blend of nutrients containing nutrients that include B-complex vitamins, minerals, proteins, gamma-linolenic acid and super anti-oxidants (such as beta-carotene, vitamin $\mathrm{E}$, trace elements) and a number of unexplored bioactive compounds [80]. Compared to other microorganisms, Spirulina sp. can be cultivated in high saline water and alkaline conditions which give an advantage to function as a feedstock for livestock feed [81]. Recently, studies regarding growth and body conformation responses of genetically divergent Australian sheep to Spirulina (Arthrospira platensis) supplementation revealed that Spirulina can increase live weight, growth and body conformation significantly [82]. Feeding lipid-encapsulated algae supplements may increase $n-3$ content in milk fat without adversely affecting milk fat yield [83].

An algal supplementation level of about $10 \mathrm{~g} \mathrm{~kg}^{-1}$ of dry matter intake proved to be effective in reducing milk fat content and in modifying the milk fatty acid composition toward increased conjugated linolenic acid (CLA) and DEA concentrations [84]. A related study demonstrated that dietary supplementation with fish meal or n-3 PUFAs in early-lactating dairy cows significantly increased milk yield with no change in milk composition [85]. In addition, some sea weeds like red algae (e.g. Porphyra sp., Gracilaria sp. and Kappaphycus sp.) and brown algae (particularly Laminaria sp., Undaria sp. and Hizikia fusiforme) were used in human food exhibiting potential to be used for livestock feed. Porphyra sp., Gracilaria sp., Grateloupia sp., and Kappaphycus sp. have also been genetically transformed for enhanced production of respective products [86]. The annual Porphyra sp. harvest worldwide has been estimated to be worth of US $\$ 2.5$ billion. Porphyra sp. primarily contains vitamin A, vitamin B, vitamin $\mathrm{C}$, beta-carotene, as well as essential minerals including iodine. Besides that, a study on Laminaria digitata suggested that algae supplemented feed has increased the pig weight up to $10 \%$ on a daily basis $[1,5]$.

\section{Poultry feed}

There are more chickens in the world than any other bird; in fact, more than 50 billion chickens are reared annually as a source of food, for both their meat and eggs (http://www.ciwf.org.uk/farm_animals/poultry/). Comprehensive analyses and nutritional studies have demonstrated that algae contain proteins and these proteins are of high quality and comparable to conventional vegetable proteins [87]. Ginzberg et al. [88] studied the role of algae Porphyridium sp. as feed supplement on metabolism of chicken. It was found that cholesterol of egg yolk was reduced about $10 \%$ and color of egg yolk became darker, indicating the production of higher carotenoids [5,89]. In poultry rations, algae up to a level of $5-10 \%$ can be used safely as partial replacement for conventional proteins. Prolonged feeding of algae at higher concentrations may 
cause adverse effects. The yellow color of broiler skin and shanks as well as of egg yolk is the most important characteristic that can be influenced by feeding algae. Moreover, the Institute für Getreideverarbeitung (BergholzRehbrücke, Germany) produces a natural feed with the algae Chlorella sp. and Arthrospira sp. called Algrow [90].

\section{Aquaculture feed}

Demand for fish for human consumption has risen due to the environmental concerns over Open Ocean fishing [91]. The world market for farmed fish and aquatic edible plants was valued in 2008 at US\$106 billion. Products from fisheries and aquaculture combined are supplying the world with 142 million tonnes of protein every year (http://www.blueeconomy.eu/m/articles/view/Fish-without-Feed-Part-1-The-Market).

According to another report by United Nations Food and Agriculture Organization (www.fao.org/docrep/016/ i2727e/i2727e.pdf), in the last three decades (19802010), world food fish production of aquaculture has increased by almost 12 times, at an average annual rate of $8.8 \%$ and the world aquaculture production attained another all-time high in 2010 at 60 million tonnes (excluding aquatic plants and non-food products), with an estimated total value of US\$119 billion (http://aquabounty.com/aquaculture-market/). Non-toxic marine microalgae, including the stramenopiles Isochrysis sp., Pavlova sp. and Nannochloropsis sp. as well as various diatoms, represent the primary food source at some stages in the life cycle of most cultivated marine animals [1]. Therefore, algal biomass will be in high demand for the fish-food and aquaculture markets in the future and provide ample revenues for the algae industry [91].

A challenge in fish nutrition is to generate end products with high levels of health-promoting long chains of omega-3 fatty acids for the consumer, while reducing the use of fish oils. Omega-3 oils have a high market demand in both the human nutraceuticals and animal feed industries. This growing trend is an additional driving force for the marketing of non-marine-based omega-3 oils and alternative feed ingredients. Algae is a rich source of high quality protein, vitamins, micronutrients (trace elements), and carotenoids, Long-chain PUFAs, especially of n-3 and n-6 series such as eicosapentaenoic (EPA), docosahexaenoic (DHA), and arachidonic (AA) are considered pharmacologically important for dietetics and therapeutics [90]. Algal meal is a rich source of high-quality protein, vitamins, micronutrients (trace elements) and carotenoids, which can be used directly in aqua feeds [85]. Furthermore, fish phosphoglycerides generally contain $50 \%$ of their total fatty acids as n-3 PUFA with a ratio of 22:6 (n-3):20:5 (n-3) of about 2:1 and it can be seen most clearly in the phosphoglycerides of fish eggs [59]. In addition, better growth weight and protein efficiencies ratio of tilapia was observed when supplied with algae as nutritional source in feed. Also, Phorphidium valderianum was successfully used as feed for aquaculture (based on its nutritional performance and non-toxic properties) [5]. The diatom Thalassiosira pseudonana is widely cultivated to feed variety of mollusks, including the Pacific oyster Crassostrea gigas and rock scallops [1]. The long chain PUFAs are highly susceptible to oxidation because of their unsaturated nature; the addition of natural antioxidants to the highly unsaturated fish oil may protect it from oxidation [92].

\section{Shrimp feed}

The total global production of farmed shrimp reached more than 1.6 million tonnes in 2003, representing a value of nearly US $\$ 9,000$ million (http://fisherymanagement. wikia.com/wiki/Shrimp_farm). Shrimp farming production reached 737,200 tonnes in 1998, an increase of $12 \%$ from 1997. This increased production was mainly reported in subtropical regions of America (28\%, 457 hatcheries) and SE Asia (72\%, 3,718 hatcheries) [59]. According to Shrimp Production Review by Food and Resource Economics Department, University of Florida USA, the shrimp farming was estimated to be about 4 million metric tonnes in 2013, with $10.3 \%$ projected annual growth rate (mainly attributed to SE Asian countries and China) (http://www.gaalliance.org/update/GOAL11/DiegoValderrama.pdf). However, disease outbreaks in recent years have affected farmed Atlantic salmon in Chile, oysters in Europe, and marine shrimp farming in several countries in Asia, South America and Africa, resulting in partial or sometimes total loss of production (http://www.fao.org/ docrep/016/i2727e/i2727e.pdf). In 2010, aquaculture in China suffered production losses of 1.7 million tons caused by natural disasters, diseases and pollution. Disease outbreaks virtually wiped out marine shrimp farming production in Mozambique in 2011 (www.fao.org/docrep/ 016/i2727e/i2727e.pdf). Microalgae species Hypnea cervicornis and Cryptonemia crenulata particularly rich in protein were tested in shrimp diets. Amount of algae in fish meal resulted in significant increase in shrimp growth rates [5]. The requirement for DHA in marine fish and shrimp nutrition has been established via feeding diets containing DHA and AA; the findings revealed that shrimp rose on diets rich in DHA and AA showed significant improvement in immune parameters, such as total hemocyte count, phenoloxidase activity, superoxide dismutase activity, and bactericidal activity [93]. Recently, it has been reported that the addition of $0.5 \%$ Spirulina meal in a complete diet for shrimp (L. vannamei juveniles), with $14 \%$ of Peruvian fishmeal, has proved as a nutritionally efficient feeding attractant [94]. Through short-term feeding studies, two marine algal products (MAP) named MAP3 and MAP8 were found suitable as substitute of protein source in the feeds of 
three prominent farmed species [89]. The studies regarding the utilization of fish oil and algae as a source of PUFAs are going side by side but the trends are more inclined towards algal products. Menhaden fish oil can also be used as a source of dietary fatty acids which influence the composition of Pacific white shrimp muscle tissue by exhibiting significantly higher shrimp muscle DHA level [95]. As fish meal content, DHA is required for the production of ecdysone for molting, growth and egg production. The mechanism involves the biological membranes rich in di-22:6 (n-3) phosphoglycerides which is relatively constant in the face of changing environmental variables like temperature, pressure, and salinity [59].

\section{Conclusion}

Microalgae have multiple potential to produce high-valued products and there is an urgent need of awareness makes these biomolecules popular in the world to meet the increasing demands with respect to population. Most of these biomolecules are not produced in the animal/human body but termed as essential; therefore, it is highly recommended to make these biomolecules available for food and feed purposes. Although the production of biomolecules from algae requires some awareness regarding technology and market value at the industrial and farmer level, it has been proved that these biomolecules can be produced using algae as a potential source at small or large scale. The demanding market of these biomolecules is quite convincing to stimulate research interests leading to production programs by the related organizations. Algae culturing got attention because of its biofuel producing characteristics but the awareness regarding cultivation technologies may also lead to set trends for biomolecule production as a pharmaceutical or nutritional product. The production of biomolecules from algae and their subsequent utilization in animal and aquaculture feed may support the objectives to establish industry from microalgae at domestic or industrial scale. Some of the biomolecules can be produced as a byproduct while producing biofuel from algae as a main targeted product. Eighty-two percent of the world fish stocks are overexploited, depleted or endangered, while demand for fish protein is exploding. With the world population expected to reach 9 billion by 2050, demand for critical sources of protein continues to outstrip supply.

\section{Consent}

Written informed consent was obtained from the patient for the publication of this report and any accompanying images.

\section{Abbreviations}

AA: Arachidonic acid; CLA: Conjugated linolenic acid; DEA: Drug Enforcement agency; DHA: Docosahexaenoic acid; DNA: Deoxyribonucleic acid; EDTA: Ethylene diamine tetra acetic acid; EPA: Eicosapentaenoic acid; GLA: (Gamma) Y-linolenic acid; HIV: Human immunodeficiency virus;
LGBP: Lipopolysaccharide and beta-1,3-glucan binding protei; LT: Leukotrienes; M: Molar; MAP: Marine algal products; MGO: Marigold Orange; PG: Prostaglandins; PPAR: Peroxisome Proliferator-activated receptors; SE: South East; Sp: Specie; TX: Thromboxanes; UV: Ultraviolet; UVA: Ultraviolet A.

\section{Competing interests}

The author's declare that they have no competing interests.

\section{Authors' contributions}

ZY: As a team leader has worked for concept development leading to a comprehensive report on algal biomolecules. EA: Has worked for writing, editing, and presenting the facts in the form of a review. AZ: Has worked for literature review, writing, and designing a review report. MM: Was also involved in literature review and extracting facts and figures for this report. MS: Was involved in supervision for designing manuscript. All authors read and approved the final manuscript.

\section{Acknowledgements}

Authors, acknowledge the University Kebangsaan Malaysia for providing infrastructure and funding to facilitate the preparation of this review report.

\section{Author details}

'Department of Chemical \& Process Engineering Faculty of Engineering \& Built Environment, University Kebangsaan Malaysia, 43600 Bangi, Malaysia. ${ }^{2}$ Centre for Energy Systems, National University of Sciences and Technology, Sector $\mathrm{H}-12$, Islamabad, Pakistan.

Received: 28 May 2013 Accepted: 31 December 2013

Published: 19 May 2014

\section{References}

1. Graham JE, Wilcox LW, Graham LE: Algae. City: Pearson Education; 2009.

2. Preisig HR, Andersen RA: Historical review of algal culturing techniques. In Algal Culturing Techniques. Edited by Andersen RA. London: Elsevier Academic Press; 2005:1-12

3. Del Campo JA, García-González M, Guerrero MG: Outdoor cultivation of microalgae for carotenoid production: current state and perspectives. Appl Microbiol Biot 2007, 74:1163-1174.

4. Spolaore $P$, Joannis-Cassan C, Duran E, Isambert A: Commercial applications of microalgae. J Biosci Bioeng 2006, 101:87-96.

5. Harun R, Singh M, Forde GM, Danquah MK: Bioprocess engineering of microalgae to produce a variety of consumer products. Renew Sust Energ Rev 2010, 14:1037-1047.

6. Naguib YMA: Antioxidant activities of astaxanthin and related carotenoids. J Ag Food Chem 2000, 48:1150-1154.

7. Kupcinskas L, Lafolie P, Lignell $\AA$, Kiudelis $G$, Jonaitis L, Adamonis K, Andersen LP, Wadström T: Efficacy of the natural antioxidant astaxanthin in the treatment of functional dyspepsia in patients with or without Helicobacter pylori infection: A prospective, randomized, double blind, and placebo-controlled study. Phytomedicine 2008, 15:391-399.

8. Nakagawa K, Kiko T, Miyazawa T, Burdeos GC, Kimura F, Satoh A, Miyazawa $\mathrm{T}$ : Antioxidant effect of astaxanthin on phospholipid peroxidation in human erythrocytes. Bri J Nutr 2011, 105:1563-1571.

9. Canales-Gómez E, Correa G, Viana MT: Effect of commercial carotene pigments (astaxanthin, cantaxanthin and $\beta$-carotene) in juvenile abalone Haliotis rufescens diets on the color of the shell or nacre. Vet Mexico 2010, 41:191-200.

10. Del Campo JA, Rodríguez H, Moreno J, Vargs MA, Rivas J, Guerrero MG: Accumulation of astaxanthin and lutein in Chlorella zofingiensis (Chlorophyta). Appl Microbiol Biot 2004, 64:848-854.

11. Zhao LY, Chen G, Zhao G, Hu X: Optimization of microwave-assisted extraction of astaxanthin from Haematococcus pluvialis by response surface methodology and antioxidant activities of the extracts. Separ Sci Technol 2009, 44:243-262.

12. Rodríguez-Sáiz M, de la Fuente $J$, Barredo $\mathrm{J}$ : Xanthophyllomyces dendrorhous for the industrial production of astaxanthin. Appl Microbiol Biot 2010, 88:645-658.

13. Yuan J-P, Peng J, Yin K, Wang J-H: Potential health-promoting effects of astaxanthin: a high-value carotenoid mostly from microalgae. Mol Nutr Food Res 2011, 55:150-165. 
14. Yang Y, Seo JM, Nguyen A, Pham TX, Park HJ, Park Y, Kim B, Bruno RS, Lee J: Astaxanthin-rich extract from the green alga Haematococcus pluvialis lowers plasma lipid concentrations and enhances antioxidant defense in apolipoprotein E knockout mice. J Nutr 2011, 141:1611-1617.

15. Tolasa S, Cakli S, Ostermeyer U: Determination of astaxanthin and canthaxanthin in salmonid. Eur Food Res Technol 2005, 221:787-791.

16. Dominguez A, Ferreira M, Coutinho P, Fábregas J, Otero A: Delivery of astaxanthin from Haematococcus pluvialis to the aquaculture food chain. Aquaculture 2005, 250:424-430.

17. Guerin M, Huntley ME, Olaizola M: Haematococcus astaxanthin: applications for human health and nutrition. Trends Biotechnol 2003, 21:210-216.

18. Sheikhzadeh N, Tayefi-Nasrabadi H, Oushani AK, Enferadi MHN: Effects of Haematococcus pluvialis supplementation on antioxidant system and metabolism in rainbow trout (Oncorhynchus mykiss). Fish Physiol Biochem 2012, 38:413-419.

19. Lyons NM, O'Brien NM: Modulatory effects of an algal extract containing astaxanthin on UVA-irradiated cells in culture. J Dermatol Sci 2002, 30:73-84.

20. Cysewski GR, Lorenz RT: Industrial production of microalgal cell-mass and secondary products - species of high Potential: Haematococcus. In Handbook of Microalgal Culture Biotechnology and Applied Phycology. Edited by Richmond A. Oxford: Blackwell Publishing Ltd; 2004:281-288.

21. Landrum JT, Bone RA: Lutein, zeaxanthin, and the macular pigment. Arch Biochem Biophys 2001, 385:28-40.

22. Shi X-M, Chen F, Yuan J-P, Chen H: Heterotrophic production of lutein by selected Chlorella strains. J App/ Phycol 1997, 9:445-450.

23. Zhang X-W, Shi X-M, Chen F: A kinetic model for lutein production by the green microalga Chlorella protothecoides in heterotrophic culture. $J$ Ind Microbiol Biot 1999, 23:503-507.

24. Wu Z-Y, Shi C-L, Shi X-M: Modeling of lutein production by heterotrophic Chlorella in batch and fed-batch cultures. World J Microb Biot 2007, 23:1233-1238.

25. Bhattacharyya S, Datta S, Mallick B, Dhar P, Ghosh S: Lutein content and in vitro antioxidant activity of different cultivars of Indian marigold flower (Tagetes patula L.) extracts. J Agr Food Chem 2010, 58:8259-8264.

26. Christaki E, Bonos E, Giannenas I, Florou-Paneri P: Functional properties of carotenoids originating from algae. J Sci Food Agr 2012, 93:5-11.

27. Wei D, Chen F, Chen G, Zhang XW, Liu LJ, Zhang H: Enhanced production of lutein in heterotrophic Chlorella protothecoides by oxidative stress. Sci China Ser C 2008, 51:1088-1093.

28. Becker W: Microalgae in human and animal nutrition. In Handbook of Microalgal Culture Biotechnology and Applied Phycology. Edited by Richmond A. Oxford: Blackwell Publishing Ltd; 2004:312-351.

29. Lers $A$, Biener $Y$, Zamir A: Photoinduction of massive $\beta$-carotene accumulation by the alga Dunaliella bardawil: Kinetics and dependence on gene activation. Plant Physiol 1990, 93:389-395.

30. Ben-Amotz A: Industrial production of microalagal cell-mass and secondary products - major industrial species Dunaliella. In Handbook of Microalgal Culture Biotechnology and Applied Phycology. Edited by Richmond A. UK: Blackwell Publishing Ltd; 2004:273-280.

31. Kar HK: Efficacy of beta-carotene topical application in melasma: an open clinical trial. Indian J Dermatol Ve 2002, 68:320-322.

32. Neuman I, Nahum H, Ben-Amotz A: Prevention of exercise-induced asthma by a natural isomer mixture of $\beta$-carotene. Ann Allerg Asthma Im 1999, 82:549-553.

33. Hr T, Tikellis G, Robman LD, McCarty CA, McNeil JJ: Vitamin E supplementation and macular degeneration: randomized controlled trial. BMJ 2002, 325:11-14.

34. Hall NF: Prevention of age related, macular degeneration. BMJ 2002, $325: 1-2$.

35. Humphrey AM: Chlorophyll. Food Chem 1980, 5:57-67.

36. Humphrey AM: Chlorophyll as a color and functional ingredient. J Food Sci 2004, 69:C422-C425.

37. Ferruzzi MG, Blakeslee J: Digestion, absorption, and cancer preventative activity of dietary chlorophyll derivatives. Nutr Res 2007, 27:1-12.

38. Gandul-Rojas B, Gallardo-Guerrero L, Mínguez-Mosquera IM: Influence of the chlorophyll pigment structure on its transfer from an oily food matrix to intestinal epithelium cells. J Agr Food Chem 2009, 57:5306-5314

39. Scotter MJ, Castle L, Roberts D: Method development and HPLC analysis of retail foods and beverages for copper chlorophyll (E141[i]) and chlorophyllin (E141[ii]) food colouring materials. Food Addit Contam 2005, 22:1163-1175.

40. Yoshida A, Yokono O, Oda T: Therapeutic effect of chlorophyll-a in the treatment of patients with chronic pancreatitis. Gastroenterol Jpn 1980 15:49-61.

41. Sekar S, Chandramohan M: Phycobiliproteins as a commodity: trends in applied research, patents and commercialization. J App/ Phycol 2008, 20:113-136.

42. Boussiba S, Richmond AE: Isolation and characterization of phycocyanins from blue green algae Spirulina platensis. Arch Microbiol 1979, 120:155-159.

43. Benedetti S, Benvenuti F, Pagliarani S, Francogli S, Scoglio S, Canestrani F: Antioxidant properties of a novel phycocyanin extract from the blue-green alga Aphanizomenon flos-aquae. Life Sci 2004, 75:2353-2362.

44. Hu Q: Industrial production of microalgal cell-mass and secondary products - major industrial species Arthrospira (Spirulina) platensis. In Handbook of Microalgal Culture Biotechnology and Applied Phycology. Edited by Richmond A. Oxford: Blackwell Publishing Ltd; 2004:264-272.

45. Shapiro HM, Glazer AN, Christenson L, Williams JM, Strom TB: Immunofluorescence measurement in a flow cytometer using low-power helium-neon laser excitation. Cytometry 1983, 4:276-279.

46. Patel A, Mishra S, Ghosh PK: Antioxidant potential of C-phycocyanin isolated from cyanobacterial species Lyngbya, Phormidium and Spirulina spp. Indian J Biochem Bio 2006, 43:25-31.

47. Chen T, Wong YS: In vitro antioxidant and antiproliferative activities of selenium-containing phycocyanin from selenium-enriched Spirulina platensis. J Agr Food Chem 2008, 56:4352-4358.

48. Givens DI, Gibbs RA: Very long chain $n-3$ polyunsaturated fatty acids in the food chain in the UK and the potential of animal-derived foods to increase intake. Nutrition Bull 2006, 31:104-110.

49. Frankel EN, Satué-Gracia T, Meyer AS, German BJ: Oxidative stability of fish and algae oils containing long-chain polyunsaturated fatty acids in bulk and in oil-in-water emulsions. J Agri Food Chem 2002, 50:2094-2099.

50. Bradbury J: Docosahexaenoic Acid (DHA): an ancient nutrient for the modern human brain. Nutrients 2011, 3:529-554

51. Cottin SC, Sanders TA, Hall WL: The differential effects of EPA and DHA on cardiovascular risk factors. P Nutr Soc 2011, 70:215-231.

52. Tanigai T, Ueki S, Kihara J, Kamada R, Yamauchi Y, Sokal A, Takeda M, Ito W Kayaba H, Adachi T, Ohta K, Chihara J: Docosahexaenoic Acid exerts antiinflammatory action on human eosinophils through peroxisome proliferator-activated receptor-independent mechanisms. Int Arch Allergy Imm 2012, 158:375-386

53. Thiombiano-Coulibaly N, Rocquelin G, Eymard-Duvernay S, Kiffer-Nunes J, Tapsoba S, Traoré SA: Seasonal and environmental effects on breast milk fatty acids in Burkina Faso and the need to improve the omega 3 PUFA content. Acta Paediatr 2003, 92:1388-1393.

54. Da Silva TL, Mendes A, Mendes RL, Calado V, Alves SS, Vasconcelos JMT, Reis A: Effect of $n$-dodecane on Crypthecodinium cohnii fermentations and DHA production. J Ind Microbiol Biot 2006, 33:408-416.

55. Jiang Y, Chen F, Liang S-Z: Production potential of docosahexaenoic acid by the heterotrophic marine dinoflagellate Crypthecodinium cohnii. Process Biochem 1999, 34:633-637.

56. Milledge JJ: Commercial application of microalgae other than as biofuels: a brief review. Rev Environ Sci Biotechnol 2011, 10:31-41.

57. Zittelli GC, Rodolfi L, Tredici MR: Industrial production of microalgal cell-mass and secondary products - species of high potential: mass cultivation of Nannochloropsis in Closed Systems. In Handbook of Microalgal Culture Biotechnology and Applied Phycology. Edited by Richmond A. Oxford: Blackwell Publishing Ltd; 2004:298-303.

58. Zamora O, Richmond A: Microalgae production for aquaculture. In Handbook of Microalgal Culture Biotechnology and Applied Phycology. Edited by Richmond A. Oxford: Blackwell Publishing Ltd; 2004:365-379.

59. Hemaiswarya S, Raja R, Kumar RR, Ganesan V, Anbazhagan C: Microalgae: a sustainable feed source for aquaculture. World J Microb Biot 2011, 27:1737-1746.

60. Zhang CW, Richmond A: Sustainable, high-yielding outdoor mass cultures of Chaetoceros muelleri var. subsalsum and Isochrysis galbana in vertical plate reactors. Mar Biotechnol 2003, 5:302-310.

61. Wen Z-Y, Chen F: Heterotrophic production of eicosapentaenoic acid by microalgae. Biotechnol Adv 2003, 21:273-294.

62. Arad S, Richmond A: Industrial production of microalgal cell-mass and secondary products - Species of high potential: Porphyridium sp. In 
Handbook of Microalgal Culture Biotechnology and Applied Phycology. Edited by Richmond A. Oxford: Blackwell Publishing Ltd; 2004:289-297.

63. Johnson MM, Swan DD, Surette ME, Stegner J, Chilton T, Fonteh AN, Chilton FH: Dietary supplementation with g-linolenic acid alters fatty acid content and eicosanoid production in healthy humans. J Nutr 1997, 127:1435-1444

64. Fan Y-Y, Chapkin RS: Importance of dietary $Y$-linolenic acid in human health and nutrition. J Nutr 1998, 128:1411-1414.

65. Yamaguchi K: Recent advances in microalgal bioscience in Japan, with special reference to utilization of biomass and metabolites: a review. J Appl Phycol 1997, 8:487-502.

66. Riggi SJ, Di Luzio NR: Identification of a reticuloendothelial stimulating agent in zymosan. Am J Physiol 1961, 200:297-300.

67. Sahoo PK, Mukherjee SC: Effect of dietary beta-1,3 glucan on immune responses and disease resistance of healthy and aflatoxin B1-induced immunocompromised rohu (Labeo rohita Hamilton). Fish Shelffish Immun 2001, 11:683-695.

68. Iwamoto H: Industrial production of microalgal cell-mass and secondary products - major industrial species Chlorella. In Handbook of Microalgal Culture Biotechnology and Applied Phycology. Edited by Richmond A. Oxford: Blackwell Publishing Ltd; 2004:255-263.

69. Vetvicka V, Yvin J-C: Int Immunopharmacol 2004, 4:721-730.

70. Blaylock RL: Yeast $\beta-1,3-$ glucan and its use against anthrax infection and in the treatment of cancer. J Am Nutraceutical Assoc 2002, 5:3-4.

71. Vetvicka V, Terayama K, Mandevill R, Brousseau P, Kournikakis B, Ostroff G: Pilot study: orally-administered yeast $\beta 1,3$-glucan prophylactically protects against anthrax infection and cancer in mice. J Am Nutraceutical Assoc 2002, 5:1-5.

72. Amparyup P, Sutthangkul J, Charoensapsri W, Tassanakajon A: Pattern recognition protein binds to lipopolysaccharide and beta-1,3-glucan and activates shrimp prophenoloxidase system. J Biol Chem 2012, 287:10060-10069.

73. Gustafson KR, Cardellina JH 2nd, Fuller RW, Weislow OS, Kiser RF, Snader KM, Patterson GM, Boyd MR: AIDS-antiviral sulfolipids from cyanobacteria (blue-green algae). J Natl Cancer / 1989, 81:1254-1258,

74. Archer SD, McDonald KA, Jackman AP: Effect of light irradiance on the production of sulfolipids from Anabaena 7120 in a fed-batch photobioreactor. Appl Biochem Biotechnol 1997, 67:139-152.

75. Carmeli S, Moore RE, Patterson GML: Tolytoxin and new scytophycins from three species of Scytonema. J Nat Prod 1990, 53:1533-1542.

76. Patterson GML, Carmeli S: Biological effects of tolytoxin (6-hydroxy-7-Omethyl-scytophycin b), a potent bioactive metabolite from cyanobacteria. Arch Microbiol 1992, 157:406-410.

77. Han B, Gross H, Goeger DE, Moobery SL, Gerwick WH: Aurilides B and C, cancer cell toxins from a Papua New Guinea collection of the marine cyanobacterium Lyngbya majuscula. J Nat Prod 2006, 69:572-575.

78. Gross H, Goeger DE, Hills P, Moobery SL, Ballantine DL, Murray TF, Valeriote FA, Gerwick WH: Lophocladines, bioactive alkaloids from the red alga Lophocladia sp. J Nat Prod 2006, 69:640-644.

79. Singh J, Gu S: Commercialization potential of microalgae for biofuels production. Renew Sust Energ Rev 2010, 14:2596-2610.

80. Kulshreshtha A, Zacharia AJ, Jarouliya U, Bhadauriya P, Prasad GBKS, Bisen PS: Spirulina in health care management. Curr Pharm Biotechno 2008 9:400-405.

81. Costa JA, de Morais MG, Dalcanton F, Reichert CC, Durante AJ: Simultaneous cultivation of Spirulina platensis and the toxigenic cyanobacteria Microcystis aeruginosa. Z Naturforsch C 2006, 61:105-110.

82. Holman B, Kashani A, Malau-Aduli AEO: Growth and body conformation responses of genetically divergent Australian sheep to Spirulina (Arthrospira platensis) supplementation. Am J Experiment Agric 2012, 2:160-173.

83. Stamey JA, Shepherd DM, de Veth MJ, Corl BA: Use of algae or algal oil rich in $\mathrm{n}-3$ fatty acids as a feed supplement for dairy cattle. J Dairy SC 2012, 95:5269-5275

84. Boeckaert C, Vlaeminck B, Dijkstra J, Issa-Zacharia A, Van Nespen T, Van Straalen $W$, Fievez $V$ : Effect of dietary starch or micro algae supplementation on rumen fermentation and milk fatty acid composition of dairy cows. J Dairy Sci 2008, 91:4714-4727.

85. Subhadra B, Grinson G: Algal biorefinery-based industry: an approach to address fuel and food insecurity for a carbon-smart world. J Sci Food Agr 2011, 91:2-13.
86. Qin S, Jiang $P$, Tseng C: Transforming kelp into a marine bioreactor. Trends Biotechnol 2005, 23:264-268.

87. Becker EW: Micro-algae as a source of protein. Biotechnol Adv 2007 25:207-210.

88. Ginzberg A, Cohen M, Sod-Moriah UA, Shany S, Rosenshtrauch A, Arad SM: Chickens fed with biomass of the red microalga Porphyridium sp. have reduced blood cholesterol level and modified fatty acid composition in egg yolk. J Appl Phycol 2000, 12:325-330.

89. Kiron V, Phromkunthong W, Huntley M, Archibald I, De Scheemaker G: Marine microalgae from biorefinery as a potential feed protein source for Atlantic salmon, common carp and whiteleg shrimp. Aquacul Nutr 2012, 18:521-531.

90. Pulz O, Gross W: Valuable products from biotechnology of microalgae. Appl Microbiol Biot 2004, 65:635-648.

91. Anemaet IG, Bekker M, Hellingwerf KJ: Algal photosynthesis as the primary driver for a sustainable development in energy, feed, and food production. Mar Biotechnol 2010, 12:619-629.

92. Keithly JI, Kott RW, Berardinelli JG, Moreaux S, Hatfield PG: Thermogenesis, blood metabolites and hormones, and growth of lambs born to ewes supplemented with algae-derived docosahexaenoic acid. J Anim Sci 2011, 89:4305-4313.

93. Nonwachai T, Purivirojkul W, Limsuwan C, Chuchird N, Velasco M, Dhar AK: Growth, nonspecific immune characteristics, and survival upon challenge with Vibrio harveyi in Pacific white shrimp (Litopenaeus vannamei) raised on diets containing algal meal. Fish Shellfish Immun 2010, 29:298-304.

94. Silva-Neto JF, Nunes AJP, Sabry-Neto H, Sá MVC: Spirulina meal has acted as a strong feeding attractant for Litopenaeus vannamei at a very low dietary inclusion level. Aquac Res 2012, 43:430-437.

95. Perez-Velazquez M, González-Félix ML, Navarro-García G, ValenzuelaEscalante E: Nutritional value of various ray fish liver oils to the pacific white shrimp Litopenaeus vannamei. Lipids 2008, 43:1009-1016.

\section{doi:10.1186/2241-5793-21-6}

Cite this article as: Yaakob et al:: An overview: biomolecules from microalgae for animal feed and aquaculture. Journal of Biological Research-Thessaloniki 2014 21:6.

\section{Submit your next manuscript to BioMed Central and take full advantage of:}

- Convenient online submission

- Thorough peer review

- No space constraints or color figure charges

- Immediate publication on acceptance

- Inclusion in PubMed, CAS, Scopus and Google Scholar

- Research which is freely available for redistribution 